\title{
REVIEWS
}

\section{MASS MINIATURE RADIOGRAPHY OF CIVILIANS}

For the Detection of Pulmonary Tuberculosis

M.R.C. Special Report Series No. 251

By Kathleen C. Clark, P. D'Arcy Hart, Peter Kesley and Brian C. Thompson

(H.M. Stationery Office, London. 1945. Pp. 135 . $3 s$.)

The publication of this report is a notable event. In addition to presenting a detailed description of the technique, it gives a comprehensive analysis of a survey made of 21,000 persons over 14 years of age in the London area drawn from the employees of two factories, and from the Civil Service personnel of a number of Government Departments. Comparison of the results of this survey with those of other surveys of larger and smaller groups by the same and other methods (fluoroscopy, full-size radiography) and in various parts of the country shows a striking similarity in the observed incidence of newly discovered tuberculous lesions, especially in the group requiring to leave work immediately for sanatorium or equivalent treatment $(0.2$ 0.7 per cent. : 0.4 per cent. in this survey). The incidence of cases requiring out-patient medical observation, including periodic x-rays, while remaining at work was found to be 0.9 per cent., thus giving a total of "significant cases amounting to 1.3 per cent. of all persons examined in the reported survey.

The magnitude of the national problem will be apparent. The difficulty in present circumstances is to provide the necessary facilities for treatment and the authors of the report are not unmindful of it. To engage in intensive propaganda for this aspect of social medicine and to hold out hope if treatment is found to be necessary, only to find that full treatment in the best conditions is not forthcoming, will not promote the confidence which the method well merits. Experience has shown that, in spite of a widespread recognition of the value to be attached to mass radiography, a great deal of propaganda and reassurance is necessary in order to obtain a satisfactory proportion of volunteers, particularly among the workpeople in industrial areas. When the scheme is outlined to factory personnel, each workman sees himself already as one of the treatment group and reacts first with anxiety for himself and then with apprehension as to the maintenance of his family. The restriction of the scheme of allowances to pulmonary tuberculosis does not encourage men to volunteer for what is regarded by them as a health survey. The present reviewer has not heard workers lay so much emphasis on the possibility of victimization as might be anticipated from references in the report. There are many industries return to which after treatment for pulmonary tuberculosis would be ill-advised; and with the best will in the world the employer would be doing the "treatment' case a disservice in taking him back.

The services of industrial medical officers in the determination of employers' policy in this matter cannot be overstressed, and yet the report emphasizes the need to uphold the myth that these men and women are so much in the pocket of employers that is is undesirable to include them in schemes of this 'confidential' kind for the amelioration of the nation's well-being. As matters are regarded at present, the industrial medical officer is well advised to maintain an attitude of detachment towards the scheme. Let him do what he can to help organize it by all means. Increasing experience will show that the employer who employs a doctor will in no way militate against the latter's overriding pre- occupation with the health and happiness of the workpeople.

It would have appeared rational to suppose that a full knowledge of the physical condition of employees should be made available to the industrial medical officer in order to attain the best possible conditions of work for the persons involved. But if there still remains that mistrust of the employer which is a painful heritae of the discreditable past history of industrial relations, the authors of the report might have made the point that an opportunity was at hand to bring to notice the great help which could be given by doctors in industry in implementing an outstanding experiment. M. W. G.

\section{SOCIAL ASPECTS OF TUBERCULOSIS}

By S. Roodhouse Gloyne, M.D., D.P.H.

(Faber and Faber, Limited, London. 1944. Pp. 147. 8s. 6d.)

Pulmonary tuberculosis is the most important single disease which affects men and women in the prime of their life. It is a chronic disease and therefore causes a very great amount of economic distress. In medical schools, if attention is paid to the disease at all, it is largely directed to the treatment of individuals, especially by the sanatorium regime and collapse therapy; and important as these aspects are, they are only makeshifts since we know of no better treatment at the present time. Perhaps the social aspects of the disease are much more important, and this book by Gloyne, an able observer, is greatly to be welcomed, particularly during war-time. His purpose is to set forth for students of social medicine, especially health visitors and those interested in the social aspects of tuberculosis, the problems of the seed and soil of tuberculosis as they concern both the individual and the community at the present day. In order to fulfil its avowed purpose the book must be elementary, but all the same it contains a valuable collection of simple facts about tuberculosis which ought to be known by every medical practitioner. All medical students would certainly be well advised to read the book. It starts with a short historical review entitled, 'From Consumption to Tuberculosis.' This is followed by an account of the discovery of the tubercle bacillus by Koch, and of the different types of bacillus and toxin. Chapters follow on favourable and unfavourable soils for tuberculosis, classification, manifestations at different ages, bovine tuberculosis and infection and portals of entry. The prevalence of the disease and its decline during the present century are discussed, together with a short account of its manifestations in primitive races. A chapter is devoted to tuberculosis in industry. The author points out that the latest advance along the road of protection has been the application of mass miniature radiography to industry, and he wisely stresses that to be effective it must be applied in the factory at frequent and regular intervals, otherwise it is liable to create a false sense of security. Much of the chapter is devoted to a description of the various dust diseases of the lung and their relation to tuberculosis. It is a pity that the word " pneumonokoniosis' is used instead of the (unfortunate) legal contraction ' pneumokoniosis.' Further chapters discuss important subjects such as case finding and prevention, care and after care, and tuberculosis legislation. At the end is a short bibliography. The value of a bibliography is that it is easy for reference: this one is printed as text and therefore is not easy. A good bibliography would have enhanced the value of a useful, timely and welcome book. 